\title{
Consumo, digestibilidade e pH ruminal de novilhos submetidos a dietas com tortas oriundas da produção do biodiesel em substituição ao farelo de soja
}

\author{
[Intake, digestibility and ruminal $\mathrm{pH}$ of steers fed diets with pies coming from the production \\ from biodiesel to replacement soybean meal] \\ B.R. Correia ${ }^{1}$, R.L. Oliveira ${ }^{2,6}$, S.M.P.L. Jaeger ${ }^{3}$, A.R. Bagaldo ${ }^{3}$, G.G.P. Carvalho ${ }^{2}$, \\ G.J.C. Oliveira ${ }^{3}$, F.H.S. Lima ${ }^{4}$, P.A. Oliveira ${ }^{5}$ \\ ${ }^{1}$ Aluno de pós-graduação - UESB - Itapetinga, BA \\ ${ }^{2} \mathrm{UFBA}$ - Salvador, BA \\ ${ }^{3} \mathrm{UFRB}$ - Cruz das Almas, BA \\ ${ }^{4}$ Aluno de pós-graduação - PDIZ - UFPB/UFRPE/UFC - Areia, PB \\ ${ }^{5}$ Aluno de pós-graduação - UFRB - Cruz das Almas, BA \\ ${ }^{6}$ Bolsista de Produtividade - CNPq
}

\begin{abstract}
RESUMO
O experimento foi realizado com quatro novilhos Holandês x Zebu, fistulados no rúmen, mantidos em baias individuais e dispostos em um quadrado latino 4x4 repetido no tempo. Teve duração de 88 dias e os animais foram alimentados com feno de tifton-85 e mistura concentrada com farelo de soja, tortas de dendê, amendoim e girassol, que constituíram os quatro tratamentos. Avaliaram-se o consumo, a digestibilidade aparente total e o pH ruminal. O consumo de matéria seca (MS), proteína bruta (PB), carboidratos não fibrosos (CNF) e nutrientes digestíveis totais (NDT) foi menor $(\mathrm{P}<0,05)$ na dieta com torta de dendê em relação às demais. Os consumos de extrato etéreo (EE) e fibra em detergente neutro (FDN) não diferiram entre dietas $(\mathrm{P}>0,05)$. As digestibilidades totais dos nutrientes não foram influenciadas pelas dietas $(\mathrm{P}>0,05)$. A concentração do $\mathrm{pH}$ ruminal não foi influenciada pelas dietas, entretanto houve efeito do tempo de coleta. As tortas de amendoim e girassol oriundas da produção do biodiesel podem substituir o farelo de soja na dieta de novilhos. A substituição total do farelo de soja pela torta de dendê diminuiu o consumo de MS.
\end{abstract}

Palavras-chave: bovino, coproduto, ingestão, torta de oleaginosas

\begin{abstract}
The experiment was conducted with four rumen canulated Holstein-Zebu steers, kept in individual pens and distributed in a 4x4 Latin square with repeated measures of time. The experiment lasted 88 days and the animals were fed Tifton-85 hay and concentrate ration with soybean meal or one of the following cakes: palm kernel, peanuts or sunflower, which constituted the four treatments. Intake, total apparent digestibility and rumen $\mathrm{pH}$ were evaluated. Dry matter (DM), crude protein (CP), non-fiber carbohydrates (NFC) and total digestible nutrients $(T D N)$ intakes were lower $(P<0.05)$ in diets containing palm kernel cake. Intake of ether extract (EE) and neutral detergent fiber (NDF) did not differ between diets $(P>0.05)$. The total digestibility of nutrients was not affected by the diets $(P>0.05)$. Rumen $\mathrm{pH}$ was not influenced by the diets; however, it was affected by time of collection. Peanut and sunflower cake originated from the production of biodiesel can replace the soybean meal in the diet for steers. Total replacement of soybean meal with palm kernel cake decreased DM intake.
\end{abstract}

Keywords: cattle, co-product, intake, oil cake

Recebido em 19 de maio de 2010

Aceito em 4 de abril de 2011

E-mail: braulio@zootecnista.com.br 


\section{INTRODUÇÃO}

A bovinocultura tem passado por transformações com relação ao uso de insumos, principalmente em razão dos elevados custos da alimentação, que é em sua grande parte composta por concentrados à base de grãos. Alimentos alternativos para substituição dos grãos estão sendo testados como opção de redução dos custos com alimentação. As tortas oleaginosas oriundas da produção do biodiesel surgem, então, como alternativa de substituição dos componentes proteicos do concentrado, geralmente, formulado à base de farelo de soja que, atualmente, corresponde à fração de maior custo do concentrado. Nesse sentido, a utilização de alternativas alimentares de menor custo, mas que promovam bom desempenho nos animais, é necessária para melhorar a relação custo/benefício (Oliveira et al., 2010).

O uso de tortas de dendê, amendoim e girassol, oriundas da produção de biodiesel na alimentação animal, deve receber atenção, visto que apresentam significativas concentrações de proteína, que é um nutriente de alto custo unitário e importante para a manutenção e o desempenho produtivo dos bovinos. Tais tortas também possuem elevado teor de extrato etéreo e, ao substituírem alimentos tradicionais como o farelo de soja, podem interferir no consumo e na digestibilidade de nutrientes e na atividade da microbiota ruminal.

Devido às suas composições bromatológicas, as tortas em estudo podem agir sobre os fatores fisiológicos, físicos e psicogênicos que controlam o consumo (Mertens, 1987). O pH ruminal é um fator químico e fisiológico que influencia o crescimento microbiano e é influenciado pelo tipo de alimento consumido (Van Soest, 1994).

Nesse sentido, o presente trabalho foi desenvolvido para avaliar o consumo, a digestibilidade aparente total e o $\mathrm{pH}$ ruminal de novilhos Holandês $\mathrm{x}$ Zebu alimentados com tortas de dendê, amendoim e girassol, oriundas da produção de biodiesel, em substituição ao farelo de soja.

\section{MATERIAL E MÉTODOS}

Foram utilizados quatro bovinos mestiços, Holandês x Zebu, castrados, com peso corporal médio inicial de $530 \mathrm{~kg}$, fistulados no rúmen, segundo técnicas descritas por Leão e Coelho da Silva (1980).

Os animais foram distribuídos aleatoriamente em um quadrado latino (QL) 4x4, repetido no tempo, com oito períodos e quatro dietas, uma com farelo de soja e outras três com uma das tortas em estudo: dendê, amendoim e girassol. O volumoso utilizado foi o feno de tifton-85. As dietas foram formuladas para serem isonitrogenadas - $11 \%$ de proteína bruta - e isoenergéticas - 63\% de nutrientes digestíveis totais -, com relação volumoso:concentrado de 65:35, com base na matéria seca, conforme recomendações do NRC (Nutrient..., 2001) para mantença.

O período experimental foi de 88 dias, composto de oito períodos de 11 dias, divididos em sete dias para adaptação dos animais às dietas experimentais e quatro dias para coleta. Os animais foram alojados em baias individuais providas de cochos e bebedouros.

Na Tab. 1, consta a composição centesimal e nutricional das dietas. As análises bromatológicas foram realizadas segundo métodos da AOAC (Official..., 1990). As determinações de fibra em detergente neutro (FDN), fibra em detergente ácido (FDA), hemicelulose, celulose e lignina foram realizadas de acordo com o método descrito por Van Soest et al. (1991). A porcentagem de carboidratos não fibrosos (CNF) foi obtida pela equação de Sniffen et al. (1992): CNF (\%MS) = 100(\%MM+\%PB+\%EE+\%FDN), em que MM e EE são a matéria mineral e o extrato etéreo, respectivamente. Os teores de nutrientes digestíveis totais (NDT) foram obtidos por meio da soma das frações digestíveis obtidas pela equação proposta por Weiss (1999): NDT= PBD $+2,25 \times \mathrm{EED}+\mathrm{CNFD}+\mathrm{FDND}$, em que PBD, EED, CNFD e FDND são, respectivamente, proteína bruta, extrato etéreo, carboidratos não fibrosos e fibra em detergente neutro digestíveis. 


\section{Correia et al.}

Tabela 1. Composição em ingredientes e nutricional das dietas (\% MS) para novilhos submetidos a dietas com tortas oriundas da produção de biodiesel

\begin{tabular}{lrccc} 
& \multicolumn{4}{c}{ Dieta } \\
\cline { 2 - 5 } Ingrediente & $\begin{array}{r}\text { Sem torta } \\
\text { adicional }\end{array}$ & Torta de dendê & $\begin{array}{c}\text { Torta de } \\
\text { amendoim }\end{array}$ & $\begin{array}{c}\text { Torta de } \\
\text { girassol }\end{array}$ \\
\hline Milho moído & 28,61 & 16,20 & 29,31 & 27,01 \\
Farelo de soja & 3,62 & - & - & - \\
Torta de dendê & - & 15,98 & - & - \\
Torta de amendoim & - & - & 2,92 & - \\
Torta de girassol & - & - & - & 5,33 \\
Premix mineral & 1,48 & 1,52 & 1,48 & 1,36 \\
Ureia:sulfato de amônio (9:1) & 1,30 & 1,30 & 1,30 & 1,30 \\
Feno de tifton-85 & 65,00 & 65,00 & 65,00 & 65,00 \\
& & & & 94,35 \\
Matéria seca & 94,27 & 94,46 & 94,27 & 4,88 \\
Matéria mineral & 4,84 & 5,37 & 4,77 & 10,70 \\
Proteína bruta & 11,12 & 10,56 & 10,79 & 2,35 \\
Extrato etéreo & 2,35 & 3,40 & 2,52 & 54,33 \\
Fibra em detergente neutro & 53,06 & 62,01 & 53,11 & 29,40 \\
Fibra em detergente ácido & 28,44 & 33,71 & 28,44 & 27,74 \\
Carboidratos não fibrosos & 28,63 & 18,67 & 28,80 & 24,93 \\
Hemicelulose & 24,62 & 28,30 & 24,67 & 10,21 \\
Lignina & 9,87 & 14,05 & 9,95 & \\
\hline
\end{tabular}

${ }^{1}$ Níveis de garantia (por kg em elementos ativos): cálcio 240,00g; fósforo 174,00g; cobre 1.250,00mg; cobalto 100,00mg; ferro 1.795,00mg; iodo 90,00mg; manganês 2.000,00mg; selênio, 15,00mg; zinco 5.270,00mg; flúor máximo $1.740,00 \mathrm{mg}$.

A dieta foi fornecida duas vezes ao dia, às oito e às 16 horas, permitindo-se sobras de 10 a $20 \%$. Foram coletadas do oitavo ao $11^{0}$ dia do período experimental, amostras dos alimentos fornecidos e das respectivas sobras, as quais foram acondicionadas em sacos plásticos, etiquetadas e armazenadas a $-20^{\circ} \mathrm{C}$ para posteriores análises.

Para determinação da excreção fecal, foram realizadas duas coletas de fezes por dia com intervalos de quatro horas, iniciando-se no oitavo dia do experimento, às 8 horas da manhã, e terminando no $11^{\circ}$ dia, às $18 \mathrm{~h}$, em cada período. As amostras de fezes, colhidas diretamente no reto dos animais, foram colocadas em sacos plásticos, identificadas e armazenadas a $-20^{\circ} \mathrm{C}$ para posteriores análises.

O consumo diário foi mensurado por meio de pesagem do alimento fornecido e das respectivas sobras, por animal, em cada período de coleta.

Para obtenção da excreção de MS fecal com o objetivo de estimar a digestão total, foi utilizada a FDN indigestível (FDNi) como indicador. As amostras de alimentos, sobras e fezes foram incubadas in situ no rúmen em sacos de náilon, por 144h, segundo método descrito por Cochran et al. (1986). O material remanescente da incubação foi submetido à extração com solução em detergente neutro, e o resíduo foi considerado FDNi.

Foram colhidos $100 \mathrm{~mL}$ de líquido ruminal, por meio da cânula ruminal, no $11^{0}$ dia de cada período do QL, com intervalo de duas horas entre cada coleta. Os horários de coleta obedeceram ao fornecimento da ração, isto é, hora zero, correspondente à coleta antecedente à alimentação dos animais, e duas, quatro e seis horas depois do fornecimento da dieta aos animais, pela manhã. As amostras de líquido ruminal foram colhidas em quatro pontos diferentes do rúmen e depois filtradas em duas camadas de pano para posterior avaliação do $\mathrm{pH}$, que foi obtido imediatamente após a filtragem do líquido em um peagâmetro digital.

As variáveis relacionadas com os tratamentos foram submetidas à análise de variância, e as comparações entre os períodos e tratamentos foram feitas pelo teste de Tukey, por meio do procedimento GLM do sistema estatístico SAS (SAS, 1990), a 5\% de significância. 
A variável $\mathrm{pH}$ ruminal foi analisada num esquema de parcelas subdivididas, em que as dietas constituíram as parcelas, e os tempos de coleta as subparcelas.

\section{RESULTADOS E DISCUSSÃO}

Observou-se que a dieta com torta de dendê proporcionou o menor consumo de MS $(\mathrm{P}<0,05)$ em relação às demais dietas (Tab. 2). Isto pode ser interpretado como decorrência do elevado teor de FDN da dieta com torta de dendê (Tab. 1), em relação às demais. Mertens (1994) relatou que alta concentração de FDN no rúmen- retículo causa limitação física, diminuindo o trânsito no trato gastrointestinal que provoca o efeito de enchimento no animal, limitando o consumo de MS. Se a densidade energética for elevada, ou a concentração de fibra for baixa em relação às exigências, a ingestão passa a ser limitada pela demanda fisiológica de energia. A correlação existente entre ingestão de FDN, ruminação e salivação é indispensável para manter a atividade ruminal e o consumo de alimentos. A resposta negativa para o consumo de MS da dieta com torta de dendê, neste estudo, está relacionada à fração de FDN e não à densidade energética da dieta.

Tabela 2. Consumos médios diários de frações nutricionais por novilhos submetidos a dietas com tortas oriundas da produção de biodiesel em substituição ao farelo de soja

\begin{tabular}{|c|c|c|c|c|c|}
\hline \multirow[b]{2}{*}{ Item } & \multicolumn{4}{|c|}{ Dieta } & \multirow[b]{2}{*}{$\mathrm{CV} \%$} \\
\hline & $\begin{array}{l}\text { Sem torta } \\
\text { adicional }\end{array}$ & $\begin{array}{c}\text { Torta de } \\
\text { dendê }\end{array}$ & $\begin{array}{c}\text { Torta de } \\
\text { amendoim }\end{array}$ & Torta de girassol & \\
\hline \multicolumn{6}{|c|}{ Matéria seca } \\
\hline $\mathrm{kg} / \mathrm{dia}$ & $12,13 a$ & 9,90b & $11,99 a$ & $12,33 a$ & 10,21 \\
\hline$\%$ PC & $2,17 \mathrm{a}$ & $1,75 b$ & $2,12 \mathrm{a}$ & 2,16a & 10,15 \\
\hline g/kgPM & $105,30^{\mathrm{a}}$ & $85,42 b$ & $103,08 a$ & $105,70 a$ & 10,10 \\
\hline \multicolumn{6}{|c|}{ Proteína bruta } \\
\hline $\mathrm{kg} / \mathrm{dia}$ & $1,45 a$ & $1,03 b$ & $1,39 a$ & $1,41 \mathrm{a}$ & 11,33 \\
\hline$\% \mathrm{PC}$ & $0,26 a$ & $0,18 b$ & $0,24 a$ & $0,25 a$ & 11,10 \\
\hline g/kgPM & $12,57 \mathrm{a}$ & $8,82 b$ & $11,86 a$ & $12,06 \mathrm{a}$ & 11,28 \\
\hline \multicolumn{6}{|c|}{ Extrato etéreo } \\
\hline $\mathrm{kg} / \mathrm{dia}$ & 0,30 & 0,34 & 0,32 & 0,31 & 16,51 \\
\hline$\%$ PC & 0,06 & 0,06 & 0,05 & 0,06 & 14,74 \\
\hline g/kgPM & 2,65 & 2,88 & 2,64 & 2,65 & 15,52 \\
\hline \multicolumn{6}{|c|}{ Fibra em detergente neutro } \\
\hline $\mathrm{kg} / \mathrm{dia}$ & 6,39 & 6,38 & 6,29 & 6,75 & 11,16 \\
\hline$\%$ PC & 1,14 & 1,13 & 1,11 & 1,18 & 10,44 \\
\hline g/kgPM & 55,51 & 55,12 & 54,13 & 57,86 & 10,52 \\
\hline \multicolumn{6}{|c|}{ Carboidratos não fibrosos } \\
\hline $\mathrm{kg} / \mathrm{dia}$ & $3,73 a$ & $1,88 \mathrm{~b}$ & $3,77 a$ & $3,64 a$ & 8,06 \\
\hline$\%$ PC & $0,67 a$ & $0,33 b$ & $0,66 a$ & $0,64 a$ & 9,52 \\
\hline g/kgPM & $32,38 \mathrm{a}$ & $16,16 b$ & $32,38 a$ & $31,19 a$ & 8,82 \\
\hline \multicolumn{6}{|c|}{ Nutrientes digestíveis totais } \\
\hline $\mathrm{kg} / \mathrm{dia}$ & $8,12 a$ & 6,62b & $8,13 a$ & $7,97 a$ & 10,17 \\
\hline$\%$ PC & $1,45 a$ & $1,17 b$ & 1,43a & $1,40 \mathrm{a}$ & 10,98 \\
\hline g/kgPM & $70,48 a$ & $57,10 \mathrm{~b}$ & $69,74 a$ & $68,42 \mathrm{a}$ & 10,71 \\
\hline
\end{tabular}

Médias na linha seguidas por letras distintas diferem entre si $(\mathrm{P}<0,05)$ pelo teste Tukey.

$\% \mathrm{PC}=$ porcentagem do peso corporal.

g/kgPM = grama por quilo de peso metabólico.

O maior consumo de matéria seca (Tab. 3) resultou, também, em maior consumo de $\mathrm{PB}$ $(\mathrm{P}<0,05)$ para as dietas sem torta adicional, com torta de amendoim e torta de girassol, quando comparado com à dieta com torta de dendê. $\mathrm{O}$ menor consumo de MS da dieta com torta de dendê tem como consequência menor ingestão de $\mathrm{PB}$, isto porque todas as dietas eram isonitrogenadas. 


\section{Correia et al.}

Tabela 3. Coeficientes de digestibilidade aparente total da matéria seca (CDMS), da proteína bruta (CDPB), do extrato etéreo (CDEE), da fibra em detergente neutro (CDFDN) e dos carboidratos não fibrosos (CDCNF) de dietas com tortas oriundas da produção de biodiesel para novilhos Holandês x Zebu

\begin{tabular}{|c|c|c|c|c|c|}
\hline \multirow[b]{2}{*}{ Item } & \multicolumn{4}{|c|}{ Dieta } & \multirow[b]{2}{*}{ CV\% } \\
\hline & $\begin{array}{l}\text { Sem torta } \\
\text { adicional }\end{array}$ & Torta de dendê & $\begin{array}{c}\text { Torta de } \\
\text { amendoim }\end{array}$ & Torta de girassol & \\
\hline CDMS & 61,60 & 62,52 & 62,10 & 62,31 & 4,76 \\
\hline CDPB & 71,01 & 71,81 & 71,70 & 72,74 & 5,44 \\
\hline CDEE & 76,86 & 81,23 & 80,12 & 82,39 & 8,63 \\
\hline CDFDN & 58,18 & 59,56 & 57,62 & 58,24 & 6,90 \\
\hline CDCFN & 73,15 & 72,60 & 76,40 & 75,61 & 8,68 \\
\hline
\end{tabular}

Médias na linha seguidas por letras distintas não diferem entre si $(\mathrm{P}<0,05)$ pelo teste Tukey.

Mesmo com o menor consumo de matéria seca obtido na dieta com torta de dendê, o consumo de $\mathrm{EE}$ não diferiu $(\mathrm{P}>0,05)$ entre as dietas. Isto é atribuído ao fato de a dieta com torta de dendê ter maior participação na composição da dieta, além de apresentar teor de EE mais alto quando comparada ao farelo de soja e às demais tortas (Tab. 1).

O consumo de FDN não diferiu $(\mathrm{P}>0,05)$ entre as dietas experimentais. De acordo com Mertens (1987), a ingestão de MS aumenta quando a ingestão de FDN é de 1,2 $\pm 0,1 \%$ do peso corporal (\%PC) e, acima deste valor, a repleção ruminal limitaria o consumo, o que se aplicaria às dietas avaliadas, pois o consumo de FDN observado variou de 1,11 a $1,18 \%$ de PC. Dessa forma, os consumos das dietas avaliadas seriam controlados por fatores físicos, ou seja, pelo efeito de "enchimento" nos animais (Mertens, 1987).

Foi observado menor consumo $(\mathrm{P}<0,05)$ de $\mathrm{CNF}$ e de NDT para a dieta com torta de dendê em relação às demais (Tab. 2). O menor consumo de CNF pode ser explicado pela sua menor concentração na dieta com torta de dendê, e o menor consumo de NDT está relacionado ao elevado teor de lignina e ao menor CMS da dieta com torta de dendê (Tab. 1 e 2).

Os coeficientes de digestibilidade aparente total da MS, PB, EE, FDN e CNF não diferiram $(\mathrm{P}>0,05)$ entre as dietas experimentais.

O CDMS foi semelhante entre as dietas em razão de o teor de concentrado ser o mesmo para as dietas e pelo consumo igual de FDN entre as dietas, sendo que este foi responsável pela regulação do consumo em razão do efeito físico "enchimento", o que interferiu na digestibilidade da MS. Llamas-Lamas e Combs (1991), em revisão de literatura, afirmaram que a digestibilidade total é influenciada pelo nível de consumo.

A média do CDMS das dietas no presente estudo foi de $62,1 \%$, ficando dentro da faixa encontrada em bovinos por Cassida et al. (1994), Rennó et al. (2005) e Dias et al. (2008), a qual variou de 54,9 a $75,2 \%$.

A ausência de efeito das dietas sobre o CDPB permite inferir que as tortas de dendê, amendoim e girassol oriundas da produção do biodiesel podem substituir o farelo de soja sem ocorrer alterações na digestibilidade da PB. O CDPB médio das dietas, $71,8 \%$, foi mais alto do que o descrito por Leão et al. (2004), de 56,4\%, que avaliaram níveis de ingestão em novilhos, e semelhante aos 69,5\% observados por Rennó et al. (2005), que avaliaram níveis de ureia na ração de novilhos.

$\mathrm{O}$ teor de EE das dietas não interferiu no CDEE, o que permite inferir que a substituição do farelo de soja pelas tortas estudadas não interferiu na digestibilidade dos nutrientes, mesmo estas tendo maiores teores de $\mathrm{EE}$ que o farelo de soja. A média dos valores da digestibilidade total do EE de $80,1 \%$ é semelhante às encontradas na literatura. Tibo et al. (2000), ao avaliarem a porcentagem de concentrado na ração sobre a digestibilidade em bovinos $F 1$ Nelore $\mathrm{X}$ Simental, obtiveram efeito linear crescente da digestibilidade do EE, com média de $79,7 \%$, ao usarem $50 \%$ de concentrado.

A ausência de efeito significativo da substituição do farelo de soja pelas tortas sobre CDFDN demonstra que as diferenças entre as frações das fibras das dietas não interferiram na sua 
digestibilidade, mesmo que a dieta com torta de dendê tenha apresentado maiores concentrações de FDN e lignina (Tab. 1, Fig. 1).

$\mathrm{O}$ pH não diferiu $(\mathrm{P}>0,05)$ entre as dietas. No entanto, verificou-se redução $(\mathrm{P}<0,05)$ linear nos valores de $\mathrm{pH}$ do momento do fornecimento da alimentação até seis horas após, devido, provavelmente, à intensificação do processo de fermentação pós-prandial e ao consequente aumento nas concentrações de ácidos graxos voláteis (AGVs). Outro fator que deve ser levado em consideração é que as dietas continham elevado teor de volumoso em relação ao concentrado e que a relação volumoso:concentrado era a mesma para todas as dietas; sendo assim, a taxa de fermentação dos carboidratos foi lenta devido à maior quantidade de carboidratos fibrosos oriundos do volumoso. Tal fato levou os valores de $\mathrm{pH}$ pós-prandial a variarem em faixas, relativamente altas. Os valores observados oscilaram de 6,76 a 7,33 e encontram-se acima da faixa que inibe 0 crescimento dos microrganismos celulolíticos, a qual varia de 5,0 a 5,5, segundo Hoover (1986), ou ser de 6,0, de acordo com Grant e Mertens (1992).
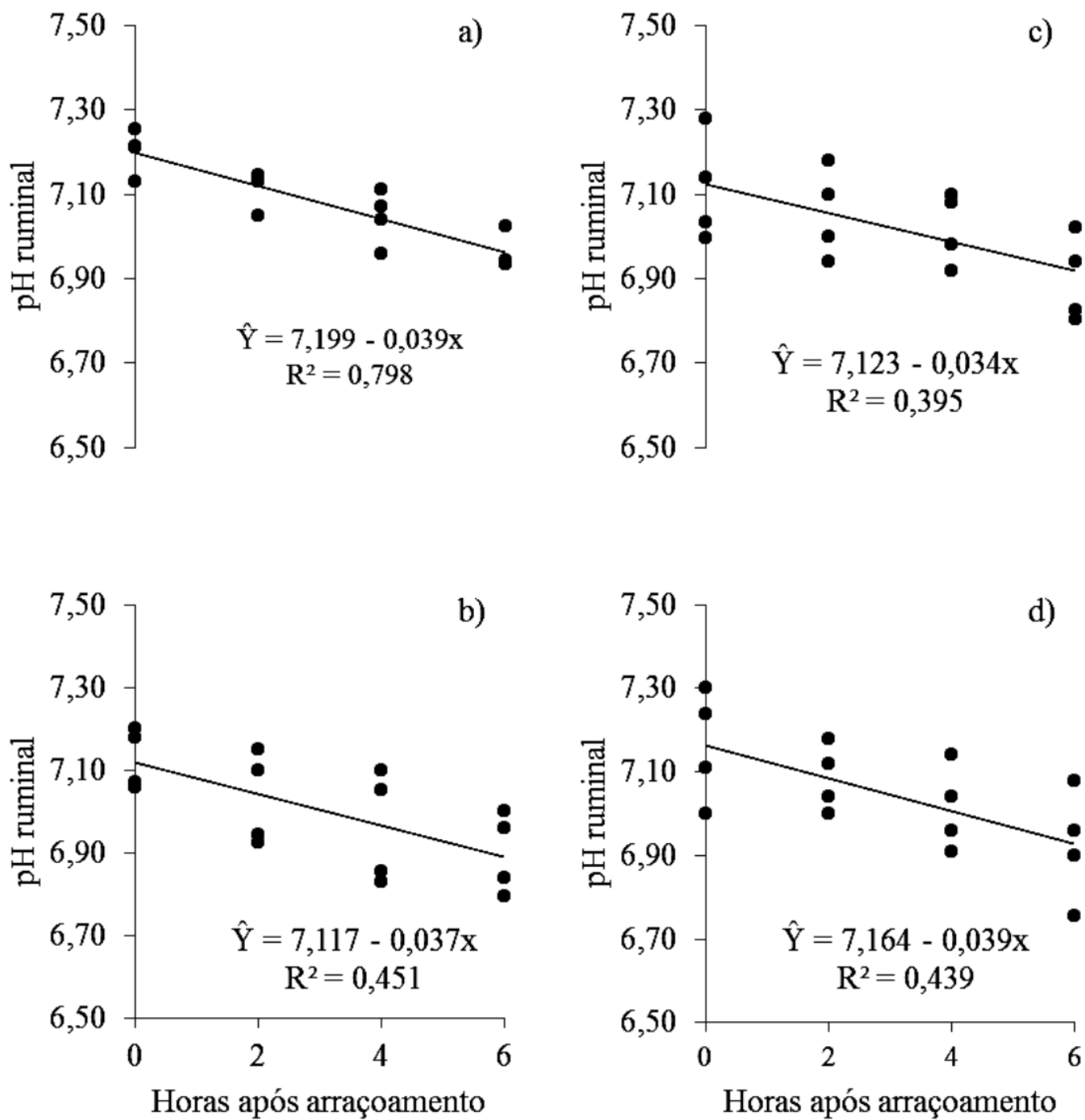

Figura 1. Concentrações do pH do líquido ruminal de novilhos submetidos a dietas com tortas oriundas da produção de biodiesel. a) sem torta adicional, b) torta de dendê, c) torta de amendoim, d) torta de girassol. 
Com o valor mínimo de $\mathrm{pH}$ obtido de 6,76, podese deduzir que não houve comprometimento na digestão ruminal da fibra, pois segundo Osrkov (1988) e Hoover (1986), a digestão estaria prejudicada com $\mathrm{pH}$ mais baixo que 6,2. Os valores de $\mathrm{pH}$ também se apresentaram dentro da faixa recomendável para o máximo crescimento microbiano, que, segundo Coelho da Silva e Leão (1979), Orskov (1988) e Hoover e Stokes (1991), devem estar entre 5,50 e 7,00.

\section{CONCLUSÕES}

As tortas de amendoim e girassol podem ser utilizadas em substituição ao farelo de soja para novilhos Holandês x Zebu, pois não afetam o consumo, a digestibilidade e o $\mathrm{pH}$ ruminal. Quanto à torta de dendê, devem ser realizados estudos com o objetivo de identificar o melhor nível de substituição do farelo de soja, visto que a substituição total afetou negativamente $\mathrm{o}$ consumo de matéria seca.

\section{REFERÊNCIAS BIBLIOGRÁFICAS}

CASSIDA, K.A.; BARTON, B.A.; HOUGH, R.L. et al. Feed intake and apparent digestibility of hay-supplemented brassica diets for lambs. $J$. Anim. Sci., v.72, p.1623-1629, 1994.

COCHRAN, R.C.; ADAMS, D.C.; WALLACE, J.D. et al. Predicting digestibility of different diets with internal markers: evaluation of four potential markers. J. Anim. Sci., v.63, p.14761483, 1986.

COELHO DA SILVA, J.F.; LEÃO, M. I. Fundamentos de nutrição dos ruminantes. Piracicaba: Livroceres, 1979. 380p.

DIAS, A.M.; SILVA, F.F.; VELOSO, C.M. et al. Bagaço de mandioca em dietas de novilhas leiteiras: consumo de nutrientes e desempenho produtivo. Arq. Bras. Med. Vet. Zootec., v.60, p.987-995, 2008.

GRANT, R.J.; MERTENS, D.R. Infleuence of butter $\mathrm{pH}$ and raw corn starch addition on in vitro fiber digestion kinetics. J. Dairy Sci., v.75, p.2762-2768, 1992.

HOOVER, W.H. Chemical factors involved in ruminal fiber digestion. J. Dairy Sci., v.69, p.2755-2766, 1986.
HOOVER, W.H.; STOKES, S.R. Balancing carbohydrates and proteins for optimum rumen microbial yield. J. Dairy Sci., v.74, p.3630-3644, 1991.

LEÃO, M.I.; COELHO DA SILVA, J.F. Técnicas de fistulação de abomaso em bezerros. In: REUNIÃO ANUAL DA SOCIEDADE BRASILEIRA DE ZOOTECNIA, 17., CONGRESSO BRASILEIRO DE ZOOTECNIA, 1., 1980, Fortaleza, Anais... Fortaleza: SBZ, 1980. 37p.

LEÃO, M.I.; VALADARES FILHO, S.C.; RENNÓ, L.N. et al. Consumos e digestibilidades aparentes totais e parciais de matéria seca, matéria orgânica, proteína bruta e extrato etéreo em novilhos submetidos a três níveis de ingestão e duas metodologias de coleta de digestas abomasal e novilhos submetidos a três níveis de ingestão e duas metodologias de coleta de digestas abomasal e omasal. Rev. Bras. Zootec., v.33, p.1604-1615, 2004.

LLAMAS-LAMAS, G.; COMBS, D.K. Effects of forage to concentrate ratio and intake level on utilization of early vegetative alfalfa silage by dairy cows. J. Dairy Sci., v.74, p. 526-536, 1991.

MERTENS, D.R. Predicting intake and digestibility using mathematical models of ruminal function. J. Anim. Sci., v.64, p.15481558, 1987.

MERTENS, D.R. Regulation of forage intake. In: FAHEY Jr.,G.C. (Ed.). Forage quality, evaluation and utilization. Madison: American Society of Agronomy, 1994. p.450-493

NUTRIENT requirements of dairy cattle. 7.ed. Washington: National Academiy of Sciences, 2001. 381p

OFFICIAL methods of analysis. 15.ed. Washington: AOAC, 1990.

OLIVEIRA, J.B.; PIRES, A.J.V.; CARVALHO, G.G.P. et. al. Subprodutos industriais na ensilagem de capim-elefante para cabras leiteiras: consumo, digestibilidade de nutrientes e produção de leite. Rev. Bras. Zootec., v.39, p.411-418, 2010.

ORSKOV, E. R. Nutrición protéica de los ruminantes. Zaragoga: Acribia, 1988. 157p. 
RENNÓ, L.N.; VALADARES FILHO, S.C.; VALADARES R.F.D. et al. Níveis de ureia na ração de novilhos de quatro grupos genéticos: Consumo e digestibilidades totais. Rev. Bras. Zootec., v.34, p.1775-1785, 2005.

SNIFFEN C.J.; O'CONNOR J.D.; VAN SOEST P.J. et al. A net carbohydrate and protein system for evaluation cattle diets: II. Carbohydrate and protein availability. J. Anim. Sci., v.70, p.35623577, 1992.

TIBO G.C.; VALADARES FILHO S.C.; COELHO DA SILVA, J.F. et al. Níveis de concentrado em dietas de novilhos F1 Simental $\mathrm{x}$ Nelore. 2. Balanço nitrogenado, eficiência microbiana e parâmetros ruminais. Rev. Bras. Zootec., v.29, p.921-929, 2000.
VAN SOEST, P.J.; ROBERTSON, J.B.; LEWIS, B.A. Methods for dietary fiber neutral detergent fiber, and non-starch polysaccharides in relation to animal nutrition. J. Dairy Sci., v.74, p.35833597, 1991.

Van SOEST, P.J. Nutritional ecology of ruminant. 2.ed. Ithaca: Cornell University, 1994. 476p.

WEISS, W.P. Energy prediction equations for ruminant feeds. In: CORNELL NUTRITION CONFERENCE FOR FEED MANUFACTURERS, 61., 1999, Ithaca. Proceedings... Ithaca: Cornell University, 1999. p. 176-185. 